УДК 621.327

МАЗІАШВІЛІ А. Р., аспірант кафедри транспортного зв'язку, КОРОЛЬОВА Н. А., к.т.н., доцент, доцент кафедри транспортного зв'язку (Український державний університет залізничного транспорту)

\title{
Удосконалення методу ісрархічної інтерполяції на основі використання нейронних мереж
}

3 огляду на конвергенцію мереж, обсяг переданої інформації збільиується в геометричній прогресії, у свою чергу, технічна реалізація не дає змогу використовувати широкий спектр методів стиснення з додатковим розробленням нових технічних блоків, тобто система стандартизована та сертифікована, тому кожен новий блок буде змінювати всю структуру самої системи. Для того шзоб система мала змогу використовувати додаткові процедури, є можливість на базі вже технічної реалізачії використовувати програмний продукт. 3 а даним напрямком існує багато робіт, які були запропоновані раніше (архіватори, об'єктноорієнтовані алгоритми), а також моделі модернізованих алгоритмів із самонавчанням. У рамках даної статті розглядається метод стиснення зображення для нейронних мереж, удосконалений за рахунок інтерполяиії.

Ключові слова: стиснення даних, метод стиснення, стиснення відеоданих, алгоритм компресії, математична модель.

\begin{abstract}
Постановка проблеми і аналіз літератури
В системах інфокомунікацій для остаточного вибору методу стиснення розглядається не один, а декілька параметрів, взаємопов'язаних між собою, тобто від вибору одного залежать усі інші характеристики. Також розглядаються питання, які визначають кількість операцій на передавальній та відновленій стороні, але які все одно орієнтовані за часовим інтервалом.
\end{abstract}

Мета статті: застосування математичного апарату штучних нейронних мереж для удосконалення методу ієрархічної інтерполяції.

\begin{tabular}{l}
\hline Основна частина \\
3 огляду на конвергенцію мереж, обсяг переданої \\
інформації збільшується в геометричній прогресії, у \\
свою чергу, технічна реалізація не дозволяє \\
використовувати широкий спектр методів стиснення 3 \\
додатковим розробленням нових технічних блоків, \\
тобто система стандартизована та сертифікована, тому \\
кожен новий блок буде змінювати всю структуру самої \\
системи [1]. Для того щоб система мала змогу \\
використовувати додаткові процедури, є можливість \\
на базі вже технічної реалізації використовувати \\
програмний продукт. За даним напрямком існує багато \\
робіт, які були запропоновані раніше (архіватори, \\
об'єктноорієнтовані алгоритми), а також моделі \\
модернізованих алгоритмів із самонавчанням. У \\
рамках даної статті розглядається метод стиснення \\
зображення для нейронних мереж, удосконалений за \\
рахунок інтерполяції.
\end{tabular}

(C) А. Р. Мазіашвілі, Н. А. Корольова, 2017
Метод ієрархічної інтерполяції в поєднанні 3 модифікованими алгоритмами статистичного кодування та алгоритмами на основі штучних нейронних мереж (ШНМ) складають запропоновану інформаційну технологію компресії відеоінформації, що відповідає всім переліченим вище вимогам.

\section{Метод ієрархічної інтерполяції}

Метод ієрархічної інтерполяції побудований на ідеї скорочення надмірності вхідних даних за рахунок використання зрідженого зображення для апроксимації проміжних відліків. Розглянемо таке уявлення відліків вихідного зображення $X$ розміру $N \times M$, а саме відліки, які розглядаються як масиви даних, які перетворені після ДКП:

$$
\begin{aligned}
& X=\bigcup_{r=0}^{R} X^{(r)} \\
& X^{(r)}=\left\{x(n, m):(n, m) \in I^{(r)}\right\} \\
& I^{(r)}=\left\{\left(n \cdot 2^{r}, m \cdot 2^{r}\right)\right\} /\left\{\left(n \cdot 2^{r+1}, m \cdot 2^{r+1}\right)\right\}
\end{aligned}
$$

У цьому виразі $X^{r}-r$-й ієрархічний рівень (IP) надання зображення, який задається безліччю індексів $I^{r}, r$ - номер попереднього розрахунку, $R$ - номер старшого IP.

Як результат описаний вираз не є надмірним і не збільшує обсяг вхідних даних при стисненні. Крім того, оскільки IP не перетинаються, то вони можуть 
бути закодовані послідовно, починаючи зі старшого. При цьому закодований та перекодований IP iз великим кроком використовується для апроксимації IP 3 меншим кроком. Очевидно, що при такому підході для стиснення кожного IP застосовується один і той самий алгоритм, тому можна обмежитися описом процедури кодування для IP із довільним фіксованим номером $r>R$.

\section{Процедура кодування}

\section{1. Передбачення:}

Нехай до моменту кодування відліку $x(n, m)$ треба декодувати деякий набір відліків $\bar{x}(n, m)$. Тоді на їх основі можна побудувати декілька різних процедур формування і передбаченого значення $\hat{x}(n, m)$ для відліку $x(n, m)$. Як приклад наведемо одну з них:

$\bar{x}_{r},(2 n, 2 m+1)=\left\langle\bar{x}_{r}(2 n, 2 m), \bar{x}_{r}(2 n, 2 m+2)\right\rangle$, $\bar{x}_{r}(2 n,+1,2 m)=\left\langle\bar{x}_{r}(2 n, 2 m), \bar{x}_{r}(2 n,+2,2 m)\right\rangle$,

$$
\bar{x}_{r}(2 n,+1,2 m+1)=\left\langle\begin{array}{l}
\bar{x}_{r}(2 n,+1,2 m) \\
\bar{x}_{r},(2 n, 2 m+1) \\
\bar{x}_{r}(2 n+1,2 m+2) \\
\bar{x}_{r}(2 n+2,2 m+1)
\end{array}\right\rangle \text {, }
$$

де

$$
\begin{aligned}
& \hat{x}_{r}(n, m)=\widehat{x}_{r}\left(n \cdot 2^{r}, m \cdot 2^{r}\right), \\
& \bar{x}_{r}(n, m)=\bar{x}_{r}\left(n \cdot 2^{r}, m \cdot 2^{r}\right)
\end{aligned}
$$

\section{2. Обчислення різницевого сигналу}

$$
f(n, m)=x(n, m)-\widehat{x}(n, m),(n, m) \in I^{(r)} .
$$

\section{3. Квантування різницевого сигналу}

Вид шкали квантування визначається прийнятим показником якості. При використанні критерію максимальної похибки функція квантування набуває вигляду:

$$
q(n, m)=\left(f\left(n, m+\varepsilon_{\max }\right) /\left(2 \varepsilon_{\max }+1\right)\right) .(7)
$$

Стиск досягається за рахунок зменшення розрядності або статистичного кодування сигналу $q(n, m)$. Найбільш важливою особливістю алгоритму $\epsilon$ те, що він може забезпечувати кращий ступінь стиску, ніж 1 біт/відлік, що неможливо при використанні класичного методу Хаффмена.
Для того щоб процедура передбачення працювала однаковим чином як при кодуванні (стиску), так і під час декодування даних, необхідно, щоб передбачене значення визначалося на основі не вихідних, а вже декодованих даних. Тому відразу після кодування відліку проводиться відновлення його наближеного значення. Обчислимо відновлене значення різницевого сигналу:

$$
\bar{f}(n, m)=q(n, m) \cdot\left(2 \varepsilon_{\max }+1\right),
$$

а потім треба здійснити відновлення повного сигналу:

$\bar{x}_{r}(n, m)=\bar{f}(n, m)+\widehat{x}(n, m),(n, m) \in I^{(r)}$.

На цьому процедуру кодування довільного рівня $X^{r}$ закінчено.

Описаний вище алгоритм стиснення двовимірних даних (зображень) на основі ієрархічної інтерполяції належить до класу алгоритмів 3 контрольованою вихідною похибкою відновлення i це $\epsilon$ його безумовним плюсом. Однак цей самий факт породжує основний недолік алгоритму - змінну швидкість створення вихідних повідомлень, тобто нестабільний у часі коефіцієнт стиснення. Даний недолік обмежує безпосередньо застосування алгоритму в системах формування та обробки зображень реального часу 3 фіксованою пропускною спроможністю каналів зв'язку.

Цей недолік зазвичай усувається шляхом буферизації вихідних даних (стисненого зображення) та управлінням параметрами алгоритму стиску залежно від стану буфера. Такий формат зображення робить доцільним використання поблокового стиску.

Нехай кодоване зображення являє собою безкінечно вертикальну смугу шириною М відліків. Побудуємо математичну модель, яка дискретно описує в часі процес буферизації відеоінформації, яка обробляється поблоково.

Нехай буферний запам'ятовувальний пристрій має об'єм $V_{0}$ бітів до початку обробки К-го блока, який заповнений на $V_{K_{1}}$ бітів. За квант часу формується 3 постійною швидкістю блок зображення 3 об'ємом $D V=L M b^{0}$ бітів, який кодується 3 максимальною похибкою $\varepsilon(K)$, яка забезпечує реальний стиск блока $B(K)$. За це же час до каналу зв'язку передається інформація об'ємом $\frac{B_{0} \Delta V}{b^{0}}$ бітів, де $B_{0}-$ ступінь стиску. До початку наступного кванта часу відносна наповненість буфера складатиме: 


$$
\begin{aligned}
& \bar{V}(K)=\frac{V(K)}{V_{0}}=\frac{1}{V_{0}}\left(V(K-1)+\frac{B(K) \Delta V}{b^{0}}-\frac{B_{0} \Delta V}{b^{0}}\right)= \\
& =\bar{V}(K-1)+\frac{B(K)-B_{0}}{k_{v} b^{0}}
\end{aligned}
$$

де $k_{v}=\frac{V_{0}}{\Delta V}-$ параметр буфера (відношення об'єму буфера до об’єму блока буфера).

Виходячи з виразу (1) можна записати:

$$
\widehat{H}_{q}=\left(H^{(R)}+3 \sum_{r=1}^{R} 4^{r-1} \widehat{H}^{(R-r)}\right) / 4^{R},
$$

де $\hat{H}^{(r)}$ - передбачене значення ентропії квантованого різницевого сигналу на r-мy IP. Відповідно до рекомендацій [2], будемо вважати, що розподілення ймовірностей неквантованого різницевого сигналу на кожному IP $\epsilon$ експоненціальним. Тоді при використанні виразу (3) ймовірність і-го рівня квантування може бути записана як:

$$
p_{q}^{(r)}(i)=\sum_{k=i \cdot\left(2 \varepsilon_{\max }+1\right)-\varepsilon_{\max }}^{i \cdot\left(2 \varepsilon_{\max }+1\right)+\varepsilon_{\max }}\left(\left(1-p_{r}\right) /\left(1+p_{r}\right)\right) p_{r}^{|i|}
$$

$$
\begin{aligned}
& E=\frac{1}{2} \operatorname{tr}\left(\frac{1}{2} \sum_{p=1}^{P}\left(z_{2}^{p}-\tilde{z}_{2}^{(p)}\right)\left(z_{2}^{(p)}-\tilde{z}_{2}^{(p)}\right)^{T}\right)= \\
& =\frac{1}{2} \operatorname{tr}\left(\sum_{p=1}^{P}\left(z_{2}^{(p)}-\tilde{z}_{2 / 1}^{(p)}\right)\left(z_{2}^{(p)}-\tilde{z}^{(p)} 2 / 1\right)^{T}\right)+ \\
& +\frac{1}{2} \operatorname{tr}\left(\sum_{p=1}^{P}\left(\tilde{z}_{2 / 1}^{(p)}-\tilde{z}_{2}^{(p)}\right)\left(\tilde{z}_{2 / 1}^{(p)}-\tilde{z}_{2}^{(p)}\right)^{T}\right)+ \\
& +\frac{1}{2} \operatorname{tr}\left(\sum_{p=1}^{P}\left(z_{2}^{(p)}-\tilde{z}_{2 / 1}^{(p)}\right)\left(\tilde{z}_{2 / 1}^{(p)}-\tilde{z}_{2}^{(p)}\right)^{T}\right)+ \\
& +\frac{1}{2} \operatorname{tr}\left(\sum_{p=1}^{P}\left(\tilde{z}_{2 / 1}^{(p)}-\tilde{z}_{2}^{(p)}\right)\left(z_{2}^{(p)}-\tilde{z}_{2 / 1}^{(p)}\right)\right.
\end{aligned}
$$

де $p_{r}-$ параметр згаданого експоненціального розподілення, який зв'язаний із дисперсією $D^{(r)}$ таким чином:

$D^{(r)}=a_{1} \cdot 2^{r} \ln (1 / p) D_{x}+a_{2} \varepsilon_{\max }^{2}$.

Таким чином, отримано залежність:

$\hat{H}_{q}=\hat{H}_{q}\left(p, D_{x}, \varepsilon_{\max }\right)$,

яка може бути табульована.

\section{Застосування математичного апарату нейронних мереж}

Нейромережеві технології надають сьогодні широкі можливості для вирішення завдань прогнозування, обробки сигналів i розпізнавання образів [3]. У порівнянні з традиційними методами математичної статистики, класифікації та апроксимації, ці технології забезпечують досить високу якість розв'язків при менших витратах. Здатність нейронних мереж до виявлення взаємозв'язків між різними параметрами дає можливість зобразити дані великої розмірності більш компактно. Порівняльний аналіз шарів нейронів широко використовується для квантування даних (vector quantization), що відрізняється від кластеризації тільки великим числом верифікації [4]. Це дуже поширений на практиці метод стиснення даних. Зобразимо величину середньо-квадратичної помилки у вигляді: 
$\sum_{p=1}^{P} z^{(p)}{ }_{2}^{(p), T}=(P-1) \widetilde{R}_{z 21} \widetilde{R}_{z 11}^{-1} \widetilde{R}_{z 12}^{(p)}$

$\sum_{p=1}^{P} \widetilde{z}_{2}^{(p), T}=(P-1) \widetilde{R}_{z, 21} W^{(1,) T} W^{(2), T}$

$\sum_{p=1}^{P} \widetilde{z}^{(p)}{ }_{2 / 1} \widetilde{z}_{2 / 1}^{(p), T}=(P-1) \widetilde{R}_{z, 21} \widetilde{R}_{z 11}^{-1} \widetilde{R}_{z 11}^{(p)} \widetilde{R}_{z 11}^{-1} \widetilde{R}_{z 12}=$

$=(P-1) \widetilde{R}_{z, 21} \widetilde{R}_{z 11}^{-1} \widetilde{R}_{z 12}$

$\sum_{p=1}^{P} \widetilde{z}^{(p)}{ }_{2 / 1} \widetilde{z}_{2}^{(p), T}=(P-1) \widetilde{R}_{z, 21} \widetilde{R}_{z 11}^{-1} \widetilde{R}_{z, 11} W^{(1,) T} W^{(2), T}=$

$=(P-1) \widetilde{R}_{z 21} W^{(1,) T} W^{(2), T}$

де $\tilde{z}_{2 / 1}^{(p)}$ - лінійна оцінка $z_{2}^{(p)}$ відповідно до спостереження $z_{1}^{(p)}, \tilde{z}_{2 / 1}^{(p)}=\widetilde{R}_{z 21} R_{z 11}^{-1} z_{1}^{(p)}$.

Аналіз отриманих залежностей показує високий ступінь збігу результатів виконання стиснення при безпосередньому застосуванні $\mathrm{HC} 3$ результатами, отриманими при виконанні двоетапного перетворення. У цілому слід зазначити, що при використанні довільної конфігурації вихідної частини фрагмента досягається більш високий рівень спотворення при стисненні по відношенню до випадку, коли використовується вихідна частина прямокутної форми, розміщена всередині фрагмента зображення [5]. Моделювання алгоритмів стиску для реалізації нейронних мереж подано на рисунку.

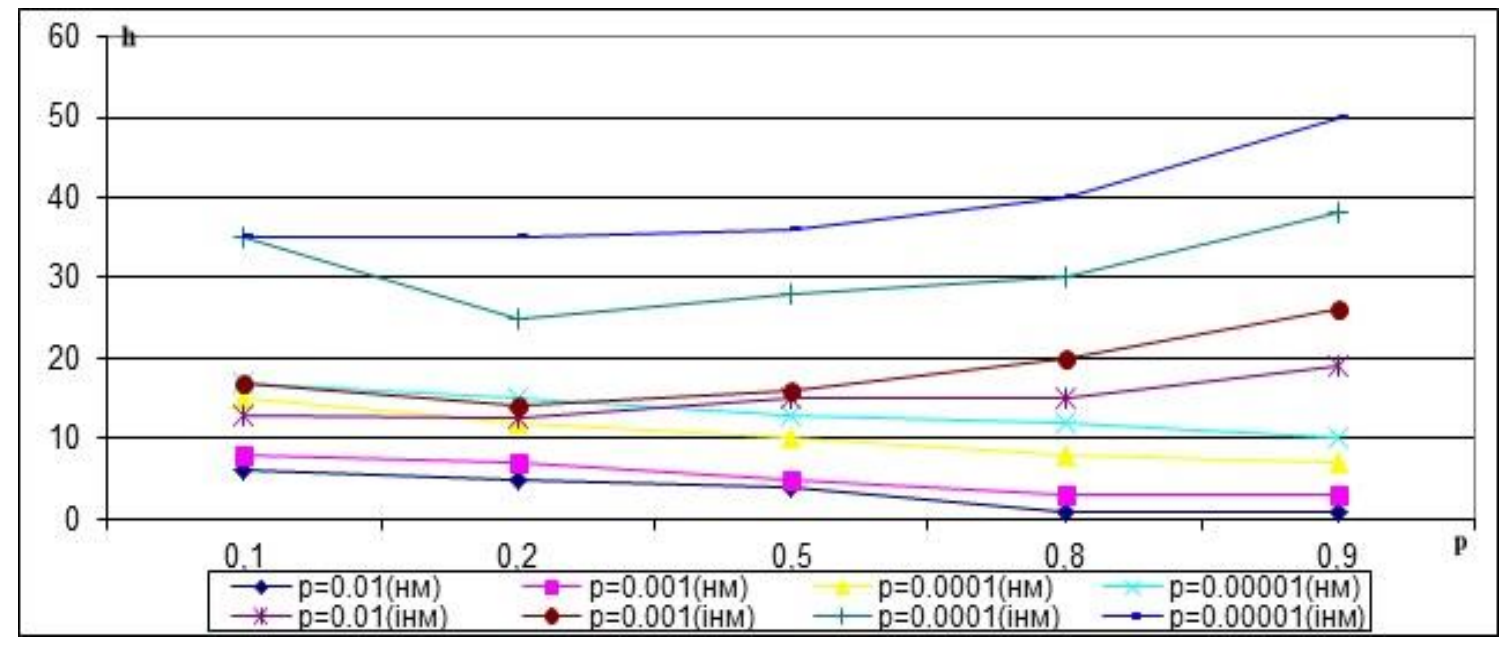

Рис. Моделювання алгоритмів стиску для реалізації нейронних мереж

\section{Отримані результати}

На основі виконаних математичних розрахунків було показано, що застосування апарату штучних нейронних мереж (ШНМ) для стиснення даних надає певні переваги, з точки зору зниження часу виконання процедури стиснення при наявності навченого перетворювача. Таким чином, нейроалгоритми $\epsilon$ важливим інструментом нелінійного аналізу, що дає змогу відносно легко знаходити способи глибокого стиснення інформації та виділення нетривіальних ознак.

Нейронна мережа має істотно кращі показники ефективності детектування у сфері слабких контрастів, ніж кожен з іiі вхідних параметрів.

\footnotetext{
Висновки

Таким чином, перспективним напрямком розвитку є підхід, в основі якого закладені ШНМ. При цьому
} 
ШНМ можуть використовуватися як при стисненні без втрат (наприклад, у статистичних методах кодування для оцінки ймовірностей появи символів), так і при реалізації стиснення 3 втратами, наприклад, у стандартах JPEG 2000/MPEG, заснованому на вейвлетперетворенні. В останньому випадку доцільно застосування IHC, що дублює векторне квантування або кластеризацію.

\section{Список літератури}

1. Претт, У.К. Цифровая обработка изображений [Текст] / У. К. Претт. - М: Мир, 1982. - Кн. 1. $312 \mathrm{c}$.

2. Комашинский, В. И. Нейронные сети и их применение в системах управления и связи [Текст] / В. И. Комашинский, Д. А. Смирнов. - М.: Телеком 2003. - 94 с.

3. Siva Nagi Reddy K. Image Compression and Reconstruction Using a New Approach By Artificial Neural Network [Text] / K. Siva Nagi Reddy, Dr. B.R. Vikram, L. Koteswara Rao, B. Sudheer Reddy // International Journal of Image Processing (IJIP) Taiwan, 2012. - Volume 6.

4. Кохонен, Т. Самоорганизующиеся карты [Текст]/ Т. Кохонен. - М: БИНОМ. Лаборатория знаний, 2008. -655 c.

5. Саймон, Хайкин. Нейронные сети: полный курс [Текст]: пер. с англ. / Хайкин Саймон. - 2-е изд. М.: Издательский дом «Вильямс», 2006. - 1104 с.

Мазиашвили А. Р., Королёва Н. $\mathbf{A .}$
Усовершенствование метода иерархической
интерполяции на основе использования нейронных
сетей. Учитывая конвергенцию сетей, объем
передающей информации увеличивается в
геометрической прогрессии, в свою очередь,
техническая реализация не позволяет использовать
широкий спектр методов сжатия, а также разработку
новых технических блоков, то есть система, она
стандартизирована и сертифицирована, поэтому
каждый новый блок, будет менять всю структуру
самой системы. Поэтому, чтобы система могла
дополнительные фунции использовать, есть
возможность на базе уже технической реализации
использовать программный продукт, который уже в
технических блоках внедрен. Исходя из этого, было
принято решение остановиться на методологии с
использованием дополнительных программных или
программно-аппаратных средств. В рамках данной
статьи рассматривается интерполяционный метод
сжатия изображения, предназначенный для решения
поставленной задачи.
Ключевые слова: сжатие данных, метод сжатия, сжатие видеоданных, алгоритм компрессии, математическая модель.
Maziashvili A. R., Korolyova N. A. Improvement of the method of hierarchical interpolation based on the use of neural networks. Given the convergence of networks, the amount of transmitting information increases in geometric progression, in turn, technical implementation does not allow the use of a wide range of compression methods, as well as the development of new technical units, that is, the system, it is standardized and certified, therefore, each new block will change the entire structure of the system itself. Therefore, in order for the system to be able to use additional features, it is possible, on the basis of technical implementation already, to use a software product that is already embedded in technical units. Based on this, it was decided to stay on the methodology, using additional software or software and hardware. In the framework of this article, an interpolation image compression method is considered, designed to solve a given problem.

The method of hierarchical interpolation in combination with the modifiers of the algorithms of statistical coding and algorithms, based on neural measurements (ANN), constitute the proposed information technology for video information compression, which meets all the above requirements.

Key words: compression of data, compression method, compression of video data, compression algorithm, mathematical model.

Надійшла 20.11.2017p.

Maziashvili A. R., postgraduate student, Department of transport communication. Ukrainian State University of Railway Transport, Kharkiv, Ukraine, ORCID: https://orcid.org/0000-0001-7778-5537, e-mail: artmazo93@gmail.com

Korolyova N.A., candidate of technical sciences, associate professor, associate professor of the department of transport communications. Ukrainian State University of Railway Transport, Kharkiv, Ukraine, e-mail: korolyova_na@ukr.net ORCID: https://orcid.org/00000001-7501-5301

Мазіашвілі Артур Рамазійович, аспірант кафедри транспортного зв'язку. Український державний університет залізничного транспорту, Харків, Україна. ORCID: https://orcid.org/0000-0001-7778-5537, e-mail:artmazo93@gmail.com

Корольова Наталія Анатоліївна к.т.н., доцент, доиент кафедри транспортного зв'язку. Украӥнський державний університет залізничного транспорту, Харків, Украӥна, е-mail: korolyova_na@ukr.net ORCID: https://orcid.org/0000-0001-7501-5301 